\title{
Defect-engineered zeolite porosity and accessibility
}

Zhengxing Qin, ${ }^{1}$ Leila Hafiz, ${ }^{2}$ Yanfeng Shen, ${ }^{1}$ StijnVan Daele, ${ }^{2}$ Philippe Boullay, ${ }^{3}$

Valerie Ruaux, ${ }^{2}$ Svetlana Mintova, ${ }^{1,2}$ Jean-Pierre Gilson, ${ }^{2}$ Valentin Valtchev ${ }^{2,4 *}$

${ }^{1}$ State Key Laboratory of Heavy Oil Processing, College of Chemical Engineering, China University of Petroleum (East China), Qingdao 266580, China

${ }^{2}$ Normandie Univ, ENSICAEN, UNICAEN, CNRS, Laboratoire Catalyse et Spectrochimie, 6 Boulevard Maréchal Juin, 14050 Caen, France

${ }^{3}$ Normandie Univ, ENSICAEN, UNICAEN, CNRS, CRISMAT, 14050 Caen, France, 6 Bd Maréchal Juin, 14000 Caen, France

${ }^{4}$ Qingdao Institute of Bioenergy and Bioprocess Technology, Chinese Academy of Sciences, Qingdao, 266101, P. R. China 


\begin{abstract}
The study reports a simple and potentially universal strategy for post-synthetic engineering of zeolite crystals. Our strategy includes the generation of point defects in zeolite crystals by preliminary etching with oxalic acid, followed by the development of these defects by $\mathrm{NH}_{4} \mathrm{~F}$ etching. Several experimental techniques were used to measure and visualize the zeolite framework dissolution as a function of intrinsic and induced defects. It is revealed that the intrinsic defects lead to the extraction of misoriented nano domains, while those introduced by oxalic acid treatment lead further to the formation of small irregular mesopores. The resultant hierarchical zeolite shows substantially improved mesoporosity, in terms of mesopore volume and spatial distribution, and outstanding micropore acid sites accessibility. These samples show superior catalytic performance in the dealkylation of a bulky molecule, 1,3,5triisopropylbenzene. Our approach highlights the significance of chemical induced extrinsic defects, which make zeolite dissolution going beyond the limits set by zeolite structure and synthesis chemistry.
\end{abstract}




\section{Introduction}

Porosity and acidity are two of the most essential properties of zeolites, which are microporous crystalline aluminosilicates comprising well-defined channels and/or cages of molecular dimension [1]. The location of well-defined acid sites in microporous space makes zeolite particularly appropriate for applications in the field of heterogeneous catalysis thanks to its unrivalled shape-selectivity [2]. On the other hand, however, the micropore confinement imposes diffusion limitations when bulky molecules are to be processed [3].

To circumvent the intra-crystalline mass transfer problem, the partial removal of framework atoms has long been employed to introduce auxiliary porous paths into the inner part of zeolite crystals [4]. This can be achieved through either dealumination or desilication $[5,6]$, noting that both dealumination and desilication, as the name indicates, are element-selective methods. A non-biased chemical etching approach, $\mathrm{NH}_{4} \mathrm{~F}$ etching, was also developed by us recently [7]. This is a method able to partially dissolve zeolite crystals without changing the framework composition [8-10]. Moreover, the removal of framework atoms begins always from extended and localized grain boundaries [10-12]. Thanks to these unique advantages, we revealed the "mosaic" architecture of zeolite crystals [10], and we prepared a "house-of-cards"like zeolite by a top-down approach for the first time [11]. Such a narrowing of the thickness of the microporous domains shortens the diffusion path length of reactants and products and increases the catalytic performance of zeolites dramatically.

One the other hand, however, the decrease of microporous domain size improves only the accessibility to the domains, but not necessarily the diffusion efficiency in a micropore. Actually, the intrinsic microporosity remains intact when the dissolution of zeolite follows a reverse "layer-by-layer" mechanism [11]. In order to face the new 
industrial challenges, there are continuous efforts to obtain zeolite materials with enhanced micropore diffusion. Several new zeolite structures with extra-large micropores were obtained [13-14], but none of them offer industrial potential due to cost and low (hydro)thermal stability.

In the present study, we present a simple chemical approach to enhance the pore volume of zeolite and increase the number of active sites accessible to molecules with a kinetic diameter larger than the micropore opening of zeolite. Our approach is based on two key factors: i) the in-situ generation of a small amount of $\mathrm{HF}_{2}^{-}$, which extracts both framework cations ( $\mathrm{Si}$ and $\mathrm{Al}$ ); and, ii) the dissolution of zeolite crystals starts preferentially from framework weak points, i.e. defect sites [10-12].

Defects are ubiquitous in crystalline materials. Zeolites, similarly to other crystalline materials, contain structural defects such as vacancies, dislocations, grain boundaries... It is known that defect sites in the zeolite framework are prone to retain coke precursors $[11,15]$. Therefore, defects are often considered as something that deteriorates the intrinsic zeolite properties. For this reason, the synthesis of zeolites in fluoride media was invoked to decrease the number of framework defects $[16,17]$. In fact, "Crystals are like people: it is the defects in them which tend to make them interesting" [18]. Indeed, our approach is fundamented on the rational use of existing and generated defects that allow us to obtain zeolite crystals with superior properties.

In the present work, we report a simple and potentially universal strategy for hierarchical zeolite design that highlighting the impact of chemical induced defects in zeolite framework, which make zeolite dissolution going beyond the limit set by zeolite structure and synthesis conditions. We will discuss in detail the structural descriptors that dictate the dissolution behavior of zeolite crystals leading to materials with a multi-model pore structure. The feasibility of this approach is exemplified by 
the treatment of the MOR-type zeolite [19], an essential active component in a number of catalytic reactions, such as carbonylation [20-22], conversion of methane into methanol [23], selective conversion of syngas [24], selective catalytic reduction of $\mathrm{NO}_{\mathrm{x}}$ [25], hydroisomerization [26] and others. Besides the 12-member ring (MR) channel running along the $\mathrm{c}$ axis, mordenite contains an 8-MR side pocket that could contribute substantially to its performance [27-28]. However this space is not readily accessible due to the minimal diameter of the pore openings [29]. Besides, the quasione-dimensional channel system of this zeolite is very prone to coke [29]. The successful engineering of the micro-environment around the active sites of mordenite can be very informative and useful for the fine-tuning of the structure of other channel-type zeolites.

\section{Experimental section}

\subsubsection{Oxalic acid and fluoride treatment of mordenite}

The parent $\mathrm{NH}_{4}$-form mordenite $(\mathrm{MOR}, \mathrm{Si} / \mathrm{Al}=6.5)$ was purchased from Zeolyst [10]. The acid treatment of MOR was performed as follows; $24 \mathrm{~g}$ of the zeolite powder was dispersed in $500 \mathrm{~g}$ of $6 \mathrm{wt} . \%$ aqueous oxalic acid solution and reacted at $90{ }^{\circ} \mathrm{C}$ for $24 \mathrm{~h}$ under stirring (ca. $400 \mathrm{rpm}$ ). The solid product was recovered by suction filtration. The sample was washed thoroughly with water and dried at $100{ }^{\circ} \mathrm{C}$ overnight. This oxalic acid treated sample was named as MOR-A.

The method used for the fluoride etching of MOR and MOR-A is reported in ref. 10. In a typical experiment, $2.5 \mathrm{~g}$ of MOR or MOR-A was dispersed in $40 \mathrm{~g}$ of $40 \mathrm{wt} . \%$ $\mathrm{NH}_{4} \mathrm{~F}$ aqueous solution and allowed to react. The reaction was carried out at $50{ }^{\circ} \mathrm{C}$ for 2 min under mechanical stirring and ultrasonication (USC $600 \mathrm{TH}, 45 \mathrm{kHz}, \mathrm{VWR}$ ). The etched products were collected by suction filtration, washed thoroughly with 
distilled water and allowed to dry at $100{ }^{\circ} \mathrm{C}$ over night. The samples derived from MOR and MOR-A respectively were labelled as follows: i) MOR-AF for the $\mathrm{NH}_{4} \mathrm{~F}$ treated sample, ii) MOR-A-AF for the sample prepared by consecutive oxalic acid and $\mathrm{NH}_{4} \mathrm{~F}$ treatment.

\subsection{Characterization methods}

X-ray diffraction measurements were performed on an X'pert Pro/PANalytical Diffractometer using $\mathrm{Cu} \mathrm{K}_{\alpha}$ radiation $(\lambda=1.5418 \AA$, $45 \mathrm{kV}, 40 \mathrm{~mA})$. The samples were studied in the $5-50^{\circ} 2 \theta$ range with a scanning step of $0.0167^{\circ} \mathrm{s}^{-1}$. Electron micrographs were taken on a JSM-7900F (JEOL) low-voltage high-resolution scanning electron microscope (SEM) equipped with a field emission gun, and a FEI $\mathrm{LaB}_{6}$ TECNAI G2 30UT transmission electron microscope (TEM) operated at $300 \mathrm{kV}$. Elemental analysis was performed by inductively coupled plasma-atomic emission spectroscopy (ICP-AES) using an OPTIMA 4300 DV (Perkin-Elmer) instrument. Nitrogen adsorptions were performed with a Mircomeritics ASAP 2020 automated gas adsorption analyzer. Prior to analysis, the samples were out gassed at $100{ }^{\circ} \mathrm{C}$ for 1 $\mathrm{h}$ and $300{ }^{\circ} \mathrm{C}$ for $10 \mathrm{~h}$. Specific surface areas were determined from the BET equation applied to the $0.01-0.06 \mathrm{P} / \mathrm{P}_{0}$ range. The total volume was taken from nitrogen adsorbed volume at $\mathrm{P} / \mathrm{P}_{0}=0.97$. The $t$-plot method, applied in the $0.4-0.8$ thickness range, was used to distinguish the micropores from the mesopores in the samples. ${ }^{27} \mathrm{Al}$ and ${ }^{29}$ Si MAS NMR spectra were recorded on a Bruker Advance $500 \mathrm{MHZ}$ spectrometer using a $4 \mathrm{~mm}$ rotor. The ${ }^{27} \mathrm{Al}$ MAS NMR spectra were recorded at 104.3 $\mathrm{MHz}$ with a 12 pulse length of $2.2 \mu$ s, a spinning rate of $14 \mathrm{kHz}$ and a recycle delay of $1 \mathrm{~s} .1 \mathrm{M} \mathrm{Al}\left(\mathrm{NO}_{3}\right)_{3}$ was used as reference for chemical shifts of ${ }^{27} \mathrm{Al}$. Infrared spectra were recorded using a Nicolet Magna 550-FT-IR spectrometer with $2 \mathrm{~cm}^{-1}$ optical resolution. Prior to the measurements, the samples were pressed into self-supporting 
discs (diameter: $1.6 \mathrm{~cm}, \sim 17 \mathrm{mg}$ ) and preheated in the IR cell attached to a vacuum line at $450{ }^{\circ} \mathrm{C}\left(2{ }^{\circ} \mathrm{C} / \mathrm{min}\right)$ for $5 \mathrm{~h}$ down to $10^{-6}$ Torr. The adsorption of $2,4,6$ trimethylpyridine (collidine) was also performed at room temperature. After reaching a pressure of 1 Torr, the sample was heated at $200{ }^{\circ} \mathrm{C}$ in the collidine atmosphere for $30-210$ min to improve the diffusion and absorption of collidine inside micropores. After establishing equilibrium at this condition, the cell was evacuated at increasing temperatures, in steps of $50{ }^{\circ} \mathrm{C}$ from 50 to $450{ }^{\circ} \mathrm{C}$. The amount of collidine adsorbed on the samples after degassing at $250{ }^{\circ} \mathrm{C}$ was used for the measure of zeolite acidity. All Spectra were normalized to the weight of wafers. The absorption bands at ca. 1637 and $1648 \mathrm{~cm}^{-1}$ were used for the quantification of the accessibility of acid sites. The extinction coefficient $\varepsilon(\text { collidine })_{1632-1648}=10.1 \mathrm{~cm} . \mu \mathrm{mol}^{-1}$ was used for collidine adsorption [30].

\subsection{Catalytic test}

The dealkylation of 1,3,5-triisopropylbenzene (TiPBz) was performed in a tubular flow reactor operating in the gas phase at atmospheric pressure. For each experiment, $25 \mathrm{mg}$ of zeolite was loaded in the reactor enclosed between two layers of inert $\mathrm{SiC}$ (200 $400 \mu \mathrm{m}$ size range). The samples were activated in a dry-air stream $(50 \mathrm{~mL}$ $\min ^{-1}$ ), first at $100{ }^{\circ} \mathrm{C}$ for $5 \mathrm{~h}$, and then the temperature raised to $450{ }^{\circ} \mathrm{C}$ (ramp of $2.5^{\circ} \mathrm{C} \cdot \mathrm{min}^{-1}$ ) and maintained $3 \mathrm{~h}$ at this final temperature. $\mathrm{N}_{2}$ was subsequently introduced and the reactor cooled-down to the reaction temperature, $350{ }^{\circ} \mathrm{C}$. A stream of $200 \mathrm{~mL} \mathrm{~min}{ }^{-1} \mathrm{~N}_{2}$ was diverted to a saturator filled with TiPBz maintained at $71{ }^{\circ} \mathrm{C}$ $\left(\mathrm{P}_{\mathrm{TiPBz}}=180 \mathrm{~Pa}\right)$. A space time of $95 \mathrm{~kg} \cdot \mathrm{s} \cdot \mathrm{mol}^{-1}$ was used. Stable conditions were established in less than 5 minutes; the first effluent was collected after $5 \mathrm{~min}$, thereafter at 15 min intervals and analyzed quantitatively on a CPG (VARIAN Cp 3800; HP-Pona 50 m, $0.2 \mathrm{~mm}, 0.5 \mu \mathrm{m}$ column), fitted with a FID detector. 


\section{Results and Discussion}

\subsection{Defect sites in the zeolite framework induced by oxalic acid leaching}

The recent research results of our group showed that the formation of secondary porosity is directly related to the intrinsic structural properties of zeolites [8-12]. Namely, the dissolution behavior of zeolites is preset by zeolite synthesis history. Following this line, a mordenite zeolite (MOR) with an initial $\mathrm{Si} / \mathrm{Al}$ ratio of 6.5 was treated by using oxalic acid, in order to introduce defect sites in the zeolite framework by selective removal of framework $\mathrm{Al}$ atoms [31]. The oxalic acid leaching resulted in the removal of ca. $75 \%$ of the framework $\mathrm{Al}$. The $\mathrm{Si} / \mathrm{Al}$ ratio of the acid leached sample, MOR-A, increased to 29.0 (Table 1). Despite the substantial loss of framework aluminum atoms, MOR-A remained highly crystalline and microporous (Figure 1, Figure 2A). However, its $\mathrm{N}_{2}$ adsorption isotherm slightly differs from that of the parent zeolite. The isotherm of MOR is type-I(a), characteristic of a microporous material (Figure 2A and Figure $\mathrm{Sl}$ ). The $\mathrm{N}_{2}$ isotherm of MOR-A remains type I, but it is closer to type-I(b) (Figure 2A and Figure Sl) according to the new IUPAC classification of physisorption isotherms [32]. The subtle change in isotherms shape serves, therefore, as the first sign of a change of the microstructure of zeolite framework, as the occurrence of type-I(b) is an indication of materials with wider micropores and possibly narrow mesopores. The pore size distribution of this sample in the 2-3 nm range also raises slightly (Figure 2B). MOR-A shows a total increase of $0.03 \mathrm{~cm}^{3} / \mathrm{g}$ in $\left(\mathrm{V}_{\text {mic }}+\mathrm{V}_{\mathrm{sec}}\right)$ in comparison to MOR (Table 1), noting that the larger micropores and/or small mesopores are difficult to be distinguished at this critical 2 $\mathrm{nm}$ pore size. Clearly, the removal of framework $\mathrm{Al}$ (Table 1) has resulted in the formation of some additional void space, which is large enough for the accommodation of $\mathrm{N}_{2}$ molecules (kinetic diameter: $0.36 \mathrm{~nm}$ ). 
Table 1. Chemical composition, product yield, specific surface area, and porosity data of the parent and modified mordenite samples.

\begin{tabular}{cccccccc}
\hline Samples & $\mathrm{Si} / \mathrm{Al}^{\mathrm{a}}$ & $\mathrm{Si} / \mathrm{Al}^{\mathrm{b}}$ & $\begin{array}{c}\mathrm{Yield}^{\mathrm{c}} \\
\mathrm{wt} \%\end{array}$ & $\begin{array}{c}\mathrm{S}_{\mathrm{BET}}{ }^{\mathrm{d}} \\
\mathrm{m}^{2} / \mathrm{g}\end{array}$ & $\begin{array}{c}\mathrm{S}_{\mathrm{ext}}^{\mathrm{e}} \\
\mathrm{m}^{2} / \mathrm{g}\end{array}$ & $\begin{array}{c}\mathrm{V}_{\mathrm{mic}^{\mathrm{e}}} \\
\mathrm{cm}^{3} / \mathrm{g}\end{array}$ & $\begin{array}{c}\mathrm{V}_{\text {sec }^{\mathrm{f}}} \\
\mathrm{cm}^{3} / \mathrm{g}\end{array}$ \\
\hline MOR & 6.5 & 6.8 & - & 489 & 25 & 0.18 & 0.06 \\
MOR-AF & 6.5 & - & 71 & 490 & 67 & 0.17 & 0.16 \\
MOR-A & 29.0 & 26.5 & - & 512 & 39 & 0.19 & 0.08 \\
MOR-A-AF & 19.8 & 20.1 & 57 & 558 & 93 & 0.19 & 0.27 \\
\hline
\end{tabular}

${ }^{\mathrm{a}} \mathrm{ICP} .{ }^{\mathrm{b}} \mathrm{EDS} .{ }^{\mathrm{c}}$ The weight percentage yield of MOR-AF (71 wt $\left.\%\right)$ and MOR-A-AF (57

wt $\%$ ) calculated based on the mass of MOR and MOR-A, respectively. ${ }^{\mathrm{d}}$ BET surface area. ${ }^{\mathrm{e}} t$-plot. ${ }^{\mathrm{f}} \mathrm{V}_{\text {total }}-\mathrm{V}_{\text {mic }}\left(\mathrm{V}_{\text {total }}\right.$ : the volume adsorbed at $\left.P / P_{0}=0.97\right)$. MOR: the parent mordenite; MOR-A: the oxalic acid treated mordenite, MOR-AF: the $\mathrm{NH}_{4} \mathrm{~F}$ treated mordenite, MOR-A-AF: the sequential oxalic acid and $\mathrm{NH}_{4} \mathrm{~F}$ treated mordenite.

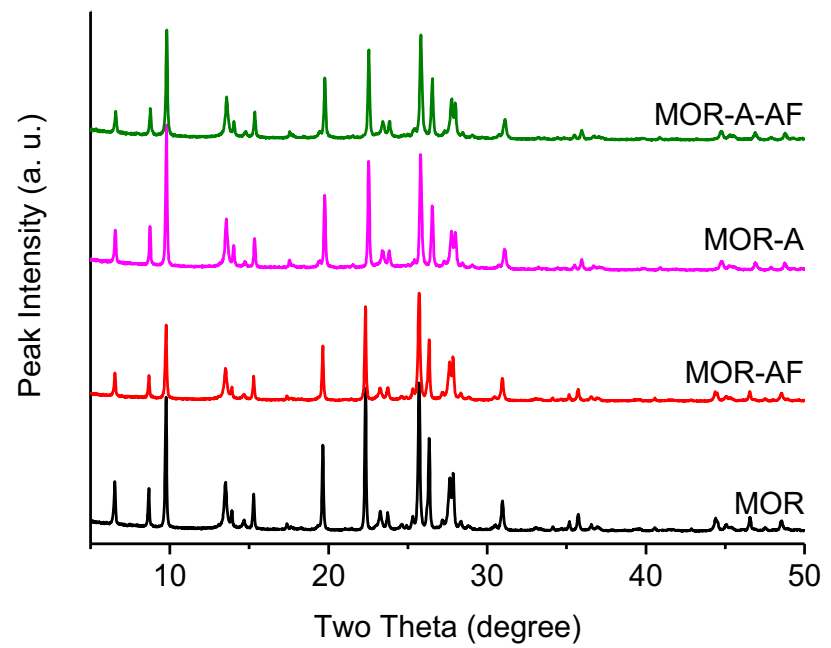

Figure 1 XRD patterns of the parent mordenite (MOR), the sample treated by oxalic acid (MOR-A), the sample treated by $\mathrm{NH}_{4} \mathrm{~F}$ (MOR-AF), and the sample treated by oxalic acid and $\mathrm{NH}_{4} \mathrm{~F}$ (MOR-A-AF). 

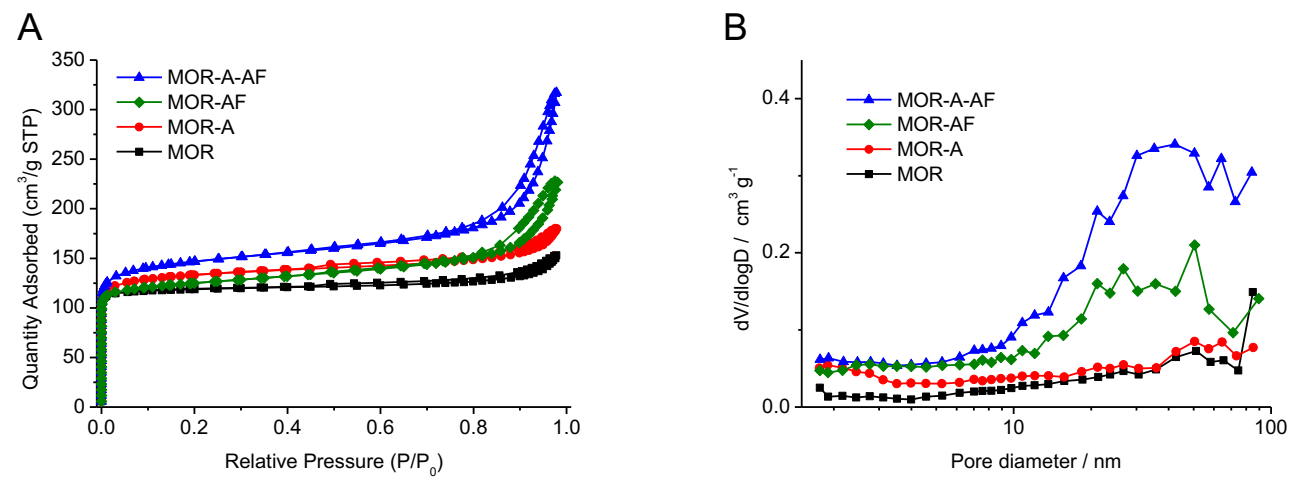

Figure $2 \mathrm{~N}_{2}$ physisorption isotherms (A) and pore size distribution (B) of MOR, MOR-A, MOR-AF, and MOR-A-AF.
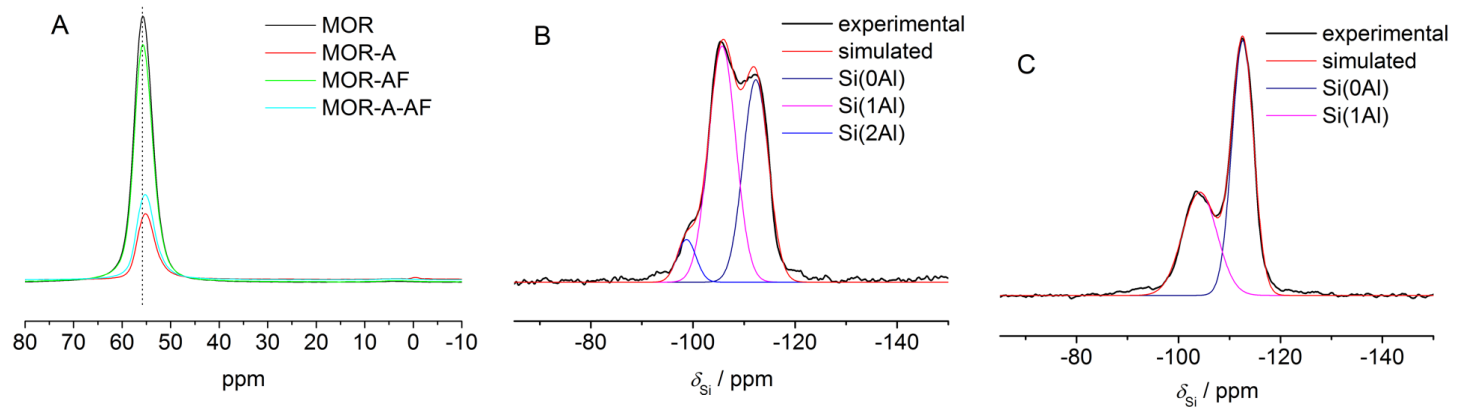

Figure 3 The ${ }^{27} \mathrm{Al}$ MAS NMR spectra of MOR, MOR-A, MOR-AF, and MOR-A-AF (A), and the deconvolution of the ${ }^{29}$ Si MAS NMR spectra of MOR (B) and MOR-A (C).

Another proof of the removal of framework $\mathrm{Al}$ and the resultant formation of framework vacancies as a result of acid leaching comes from the ${ }^{27} \mathrm{Al}$ and ${ }^{29} \mathrm{Si} \mathrm{MAS}$ NMR results (Figure 3). The quantitative ${ }^{27} \mathrm{Al}$ MAS NMR experiment shows clearly the loss of framework Al caused by acid leaching (Figure 3A). It also shows that both MOR and MOR-A are free of non-framework Al species. The ${ }^{29}$ Si MAS NMR spectrum of MOR shows clearly three peaks centered at $-99,-105$ and $-112 \mathrm{ppm}$ (Figure $3 \mathrm{~B})$, which are attributed to the $\mathrm{Si}(2 \mathrm{Al}), \mathrm{Si}(1 \mathrm{Al})$ and $\mathrm{Si}(0 \mathrm{Al})$ atoms in the zeolite framework, respectively [33]. The $\mathrm{Si} / \mathrm{Al}$ ratio of this sample determined by the 
deconvolution of the ${ }^{29} \mathrm{Si}$ MAS NMR spectrum is 6.2, which is quite close to the ICP and EDS analysis results (Table 1). The ${ }^{29}$ Si MAS NMR spectrum of MOR-A shows only two peaks sitting around -104 and -112 ppm (Figure $3 \mathrm{C}$ ). The $\mathrm{Si} / \mathrm{Al}$ ratio of this sample determined by the NMR method is 10.2 , which is much lower than the ICP and EDS data (Table 1). Apparently, defect sites assigned to Q3 groups corresponding to nonbonded defects (silanol) are present in the framework of MOR-A. Such signals increase the -104 ppm peak intensity and, as a result, the NMR analysis underestimates substantially the $\mathrm{Si} / \mathrm{Al}$ ratio of the oxalic acid dealiminated zeolite (MOR-A) [34].
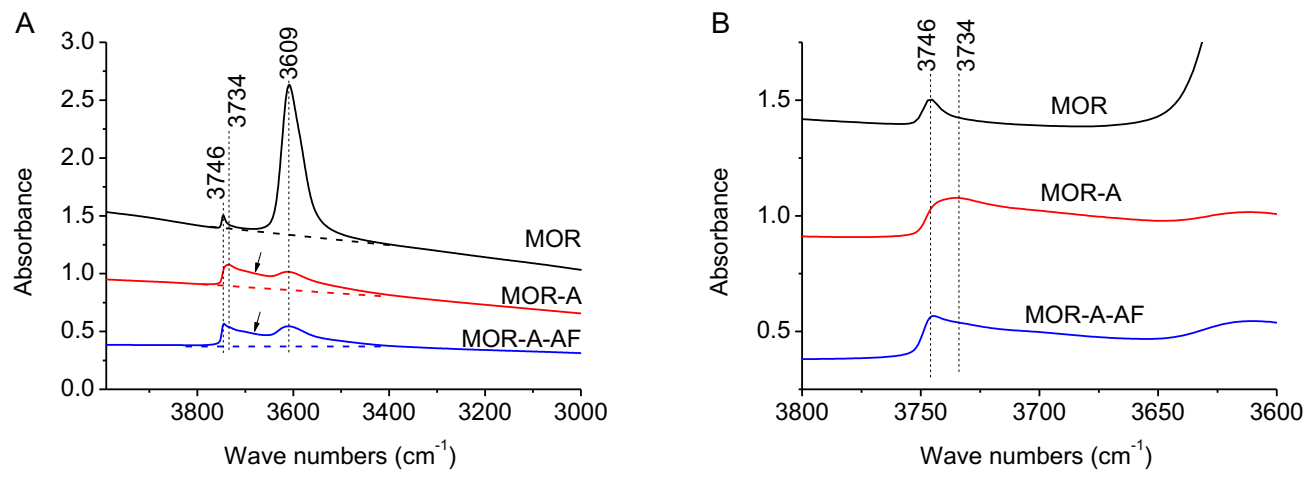

Figure 4 The IR spectra showing the $v(\mathrm{OH})$ region of MOR, MOR-A and MOR-A-AF: (A) the $3000-4000 \mathrm{~cm}^{-1}$ region, (B) the $3600-3800 \mathrm{~cm}^{-1}$ region highlighting the hydroxyl groups related to defective sites.

The structure characteristics of MOR and MOR-A were further studied by IR. For MOR, the bridging hydroxyl groups are characterized by a sharp asymmetric band centered at ca. $3609 \mathrm{~cm}^{-1}$ in the $v(\mathrm{OH})$ region (Figure 4A). A small IR band at 3746 $\mathrm{cm}^{-1}$ representing the silanol groups on the external surface of zeolite can also be clearly identified (Figure 4). The number of bridging hydroxyl groups decreases substantially after acid treatment (Figure 4A). On the contrary, the number of internal silanol groups, characterized by an IR band at ca. $3734 \mathrm{~cm}^{-1}$, increases obviously upon 
dealumination (Figure 4). Besides, there are broad bands in the region of 3650-3710 $\mathrm{cm}^{-1}$ (Figure 4A, indicated by arrow). These data show clearly that defect sites, most probably in the form of isolated silanol groups, have been introduced into the mordenite zeolite framework as desired [35].
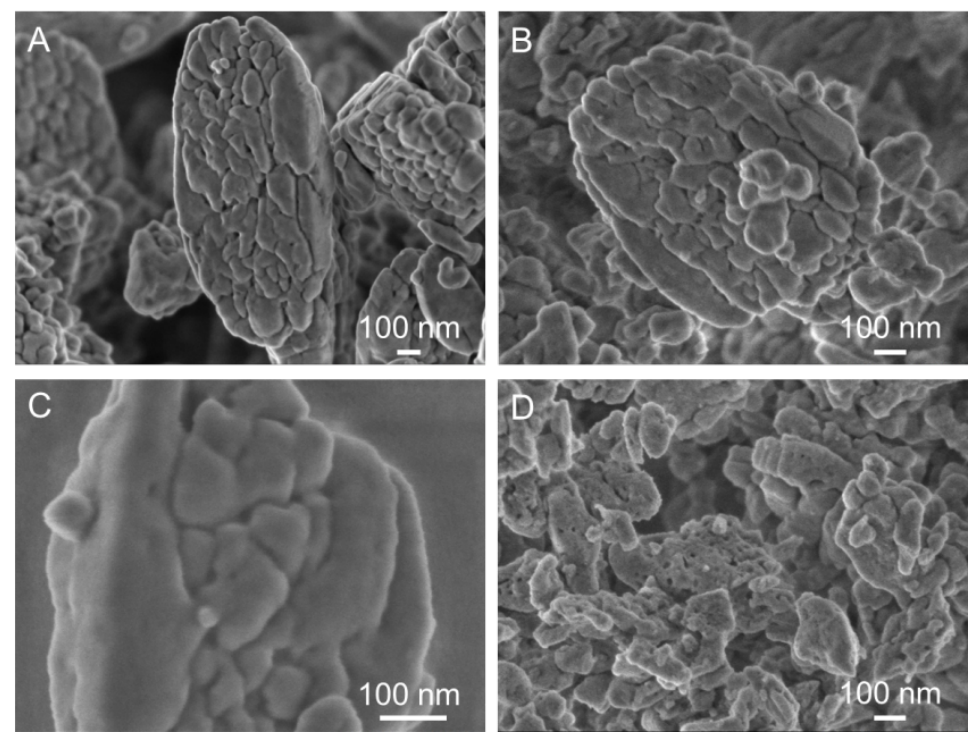

Figure 5 The high-resolution low-voltage SEM images of MOR (A), MOR-A (B), MOR-AF (C), and MOR-A-AF (D).

SEM observation shows that MOR zeolite has a particle morphology consisting of intergrown small boulder-like particles (Figure 5A). These small crystals exhibit a rather homogeneous contrast under TEM (Figure 6A), reflecting the absence of mesoporosity. The SEM image of MOR-A shows a very similar aggregative morphology like MOR (Figure 5B). The small particles also show a homogeneous contrast with distinct grain boundaries under TEM observation (Figure 6B). The darkto-light contrast, a sign of the presence of intra-particle mesopores, is absent. Apparently, the selective removal of framework aluminum only results in the formation of some localized defective sites that are documented by IR, NMR and $\mathrm{N}_{2}$ 
adsorption analysis (Figure 2-4), but are difficult to be visualized by SEM or TEM analysis.

\section{2 $\mathrm{NH}_{4} \mathrm{~F}$ etching of MOR and MOR-A}

\subsection{1 $\mathrm{NH}_{4} \mathrm{~F}$ etching of MOR}

Treating MOR with $\mathrm{NH}_{4} \mathrm{~F}$ does not change the $\mathrm{Si} / \mathrm{Al}$ ratio of the sample (MOR-AF, Table 1). This result is in agreement with our previous studies performed on MFI, FAU, and FER type zeolites [8-11]. The crystalline characteristic and micropore volume of zeolite are retained (Table 1, Figure 1). There is little increase in the fraction of narrow mesopores (Figure 2). Furthermore, the surface morphology of MOR-AF (Figure 5C) looks similar to the parent mordenite (Figure 5A). On the other hand, the $\mathrm{NH}_{4} \mathrm{~F}$ treatment results in a substantial increase in the mesopore volume (Table 1 and Figure 2). TEM reveals the formation of visible "cracks" in large platelike zeolite grains (Figure 6C). We have interpreted such splits as the gradual separation of small crystals with intergrowth interface [8-10]. Besides the diassembly of the aggregates, some large, isolated intra-particle mesopores are also formed in some crystals (Figure 7A). While the number of such pores is small at the stage of etching, an extension of $\mathrm{NH}_{4} \mathrm{~F}$ etching from $2 \mathrm{~min}$ to $25 \mathrm{~min}$ increases the number of mesopores with straight, clear-cut edges substantially (Figure 7B). These pores are spatially oriented and aligned themselves to the crystallographic axis (Figure 7B, inset). We attribute the formation of these intra-particle mesopores specifically to the mosaic structures in zeolite framework,i.e., the selective removal of hidden nanocrystalline domains [10]. 


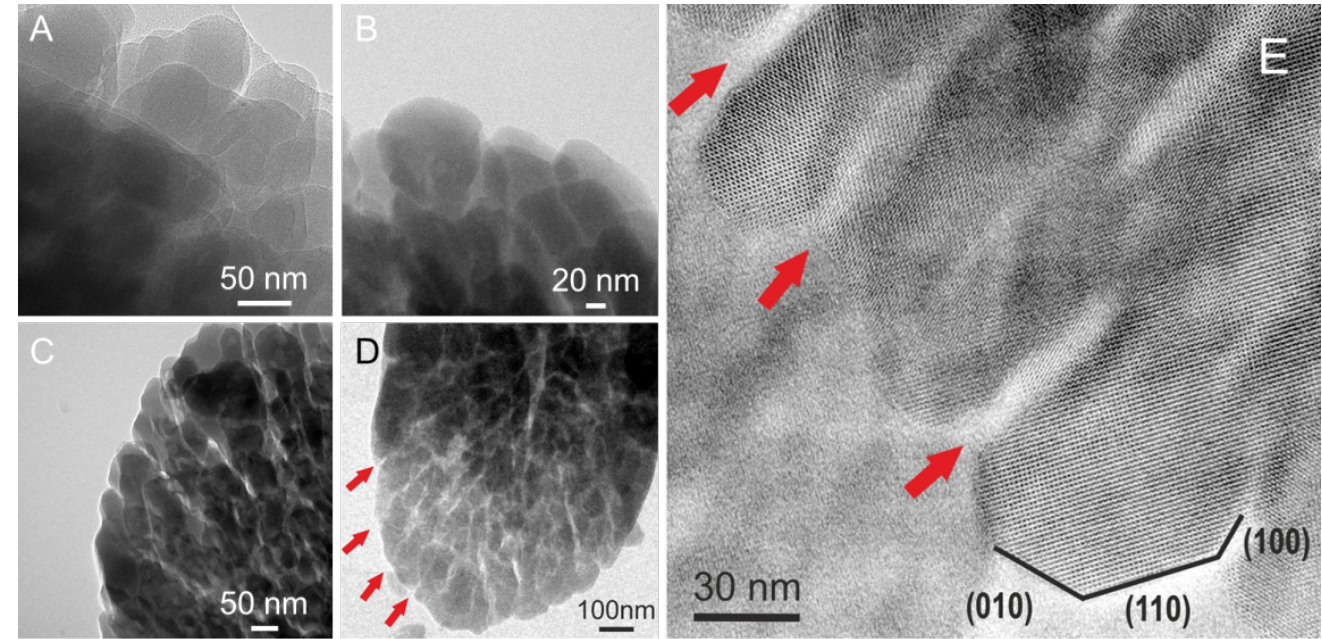

Figure 6 The TEM images of MOR (A), MOR-A (B), MOR-AF (C), and MOR-A-AF $(\mathrm{D}, \mathrm{E})$.
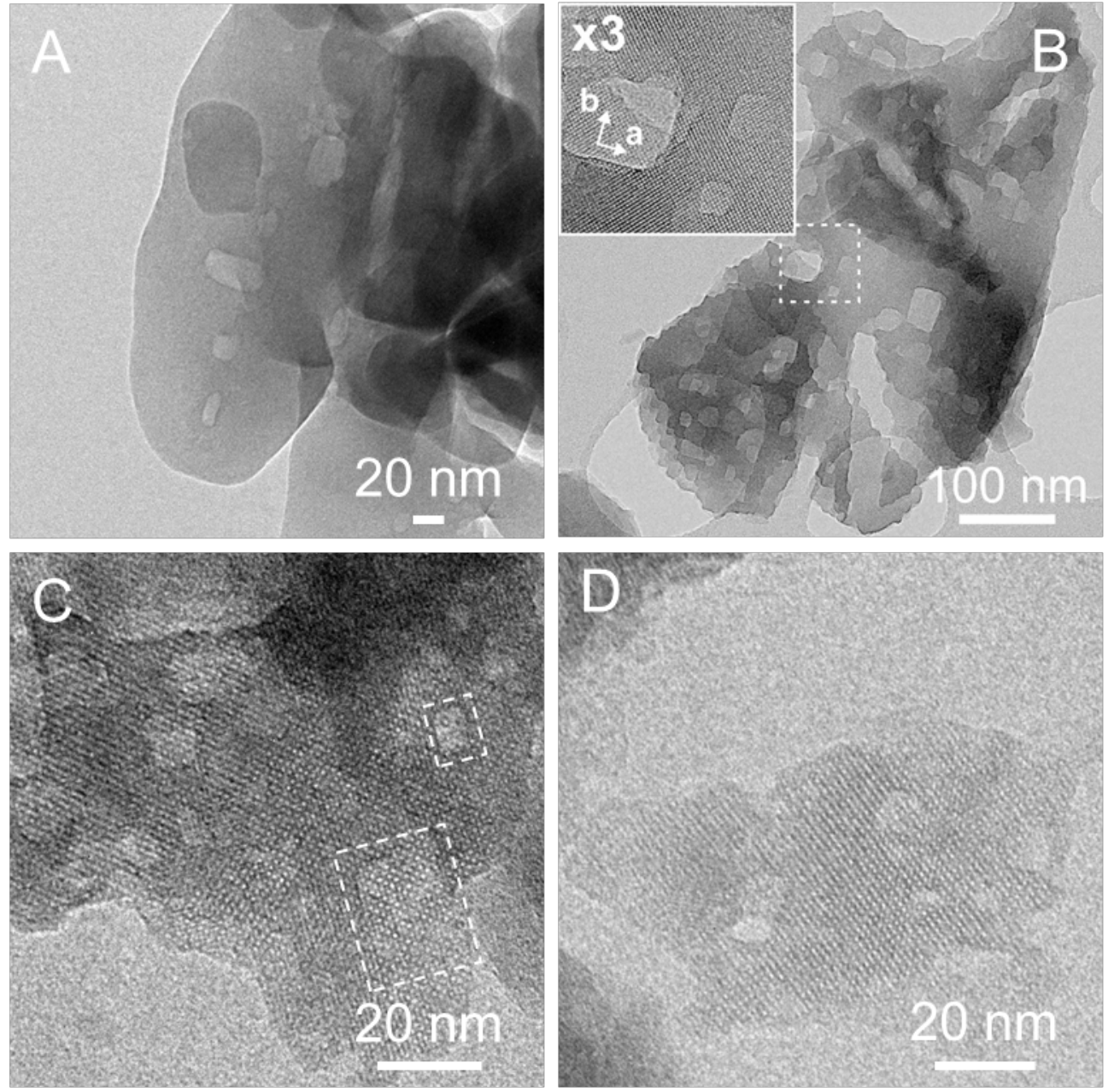

Figure 7 Representative TEM images of MOR-AF (A), a mordenite sample prepared by extended $\mathrm{NH}_{4} \mathrm{~F}$ etching of MOR (B), and MOR-A-AF (C, D). 


\subsection{2 $\mathrm{NH}_{4} \mathrm{~F}$ etching of MOR-A}

The $\mathrm{NH}_{4} \mathrm{~F}$ treatment of MOR-A results in a substantial decrease in the $\mathrm{Si} / \mathrm{Al}$ ratio (MOR-A-AF, Table 1). This is in sharp contrast to the case of MOR-AF, which shows that it is a consequence of the preliminary oxalic acid etching.

The MOR-A-AF sample remains highly crystalline (Figure 1). The micropore volume determined by t-plot is the same as the precursor, MOR-A (Table 1). Nitrogen adsorption analysis also revealed that a certain amount of mesoporosity was introduced by the fluoride treatment (MOR-A-AF, Table 1 and Figure 2). The TEM inspection shows that the MOR-A-AF is highly segmented along the interfaces between the crystals building the aggregates (Figure 6D, E), and the dark-to-light contrast is densely distributed throughout the whole particle volume. This profile contrasts sharply with the intact appearance of MOR (Figure 6A) and MOR-A (Figure 6B). Based on a careful comparison of the SEM and TEM images, one can get the impression that the mesopore density in the case of MOR-A-AF is substantially higher than that of MOR-AF (Figure 5C, D and Figure S2). This visual observation was also quantitatively confirmed by nitrogen adsorption data (Table 1 and Figure 2). The significant difference in mesoporosity (pore size, density, and morphology) between MOR-AF and MOR-A-AF samples is even more evident through the comparison of the corresponding isolated fragments. For the MOR-AF samples, only few mesopores can be observed in the bulk of the separated crystals (Figure 7A, B). Most of the mesopore size is larger than $20 \mathrm{~nm}$ along the long direction, while pores with sides shorter than $10 \mathrm{~nm}$ are rare. In the MOR-A-AF case, the number of mesopores cannot be counted accurately due to the substantially higher mesopore density (Figure 7C). Also the clear identification of the mesopore periphery is difficult. Based on a careful investigation of the TEM images, however, one can still 
distinguish between two types of pores. One type possesses a rectangle periphery or has at least some right angles (indicated with rectangles in Figure 7C, and Figure $\mathrm{S} 3 \mathrm{~A}$ ), the other is generally ill-defined in shape and much smaller in size than the regularly shaped pores (Figure 7D and Figure S3B).

While the presence of mesopores with rectangular shapes or right angles is considered as the removal of the spatially distributed hidden nano-crystalline domains, the formation mechanism of the much more irregular-shaped and smaller mesopores (Figure 7D and Figure S3B) are not related with a particular type of growth or structure-related particularities.

\subsection{Acid sites accessibility: an IR study of pyridine and collidine adsorption}

\subsubsection{Pyridine adsorption}

The adsorption of pyridine was conducted at room temperature (RT). The adsorption reached equilibrium within 15 min for all mordenite samples. The kinetic diameter of the probe molecule is $0.57 \mathrm{~nm}$ and is much smaller than the $0.7 \mathrm{~nm}$ large 12-MR channel of mordenite and thus no diffusion limitation is expected.

The treatment of MOR using $\mathrm{NH}_{4} \mathrm{~F}$ does not change the zeolite acidity. Both MOR and MOR-AF show similar Brønsted and Lewis acidity (Table 2). This is in line with the fact that $\mathrm{NH}_{4} \mathrm{~F}$ etching does not change $\mathrm{Si}$ and $\mathrm{Al}$ composition or produce extraframework $\mathrm{Al}$ species (Figure 3A). It is also a clear indication that the treatment does not change the microporous properties of mordenite. This is in line with our previous observation that the intrinsic microporosity remains intact when the dissolution of zeolite follows a reverse "layer-by-layer" mechanism [11]. 
Table 2. Acidity and accessibility of the active sites of the parent and modified mordenite samples measured by IR using pyridine (Py) and collidine (Co) as probe molecules (The unit for acid amount: $\mu \mathrm{mol} \mathrm{g}^{-1}$ ).

\begin{tabular}{|c|c|c|c|c|c|c|c|}
\hline \multirow{2}{*}{ Samples } & \multirow{2}{*}{ Acidity $^{a}$} & \multicolumn{3}{|c|}{ Acidity $^{b}$} & \multirow{2}{*}{ Acidity $^{c}$} & \multicolumn{2}{|c|}{ Accessibility } \\
\hline & & $\mathrm{B}$ & $\mathrm{L}$ & $\mathrm{B}+\mathrm{L}$ & & Py & $\mathrm{Co}$ \\
\hline MOR & 2222 & 992 & 73 & 1065 & 49 & 48 & 2 \\
\hline MOR-AF & 2222 & 909 & 82 & 991 & 418 & 45 & 19 \\
\hline MOR-A & 556 & 355 & 157 & 513 & 82 & 92 & 15 \\
\hline MOR-A-AF & 800 & 422 & 348 & 770 & 326 & 96 & 41 \\
\hline
\end{tabular}

${ }^{a}$ The acidity is calculated on the basis of the Al content by assuming that each $\mathrm{Al}$ contributes to an acid site. ${ }^{\text {b}}$ The Brønsted (B) and Lewis (L) acid amount determined by using pyridine as the probe molecular. ${ }^{\mathrm{c}}$ The acid amount determined by using collidine as the probe molecular. ${ }^{\mathrm{d}}$ Acid sites accessibility were calculated based on the total $\mathrm{Al}$ content and the amount of acid sits accessible to pyridine and collidine. MOR: the parent mordenite; MOR-A: the oxalic acid treated mordenite, MOR-AF: the $\mathrm{NH}_{4} \mathrm{~F}$ treated mordenite, MOR-A-AF: the sequential oxalic acid and $\mathrm{NH}_{4} \mathrm{~F}$ treated mordenite.

The leaching of MOR using oxalic acid decreases the total amount of acid sites substantially, in agreement with the decrease of the aluminum content (Table 1). Noteworthy, the sum of Brønsted and Lewis acidity is very close to the acid amount calculated based on the $\mathrm{Al}$ content (Table 2). If we assume that each $\mathrm{Al}$ contributes an acid site, either Brønsted or Lewis type, then it can be speculated that almost all the acid sites in MOR-A are accessible to pyridine. This is in agreement with previous finding that some of the acid sites in the side pockets of mordenite become accessible upon dealumination [35].

MOR-A-AF shows higher acid stes content than MOR-A, in line with its higher Al content. The sum of Brønsted and Lewis acidity is also very close to the acidity 
calculated based on the Al content (Table 2), indicating that the acid sites are also almost fully accessible to pyridine.

\subsubsection{Collidine adsorption}

The initial adsorption of collidine was also conducted at RT. We noticed that this molecule, with a kinetic diameter of $0.74 \mathrm{~nm}$ [36] that is larger than the pore size of mordenite, was very difficult to penetrate through the micropores of this zeolite. This can be seen from the fact that the adsorption of collidine on Brønsted acid sites at RT is slow for all mordenites (1637-1648 cm-1 bands, lines "RT" in Figure S4). The 3610 $\mathrm{cm}^{-1}$ bands intensity remains almost unchanged before and after the adsorption of collidine (lines "RT" in Figure S4). The adsorbed collidine mainly interacts with the silanol groups (1573 and 1616-1618 $\left.\mathrm{cm}^{-1}\right)$ [15] on the external surface of the zeolite (lines "RT" in Figure S4). As a result, the amount of collidine adsorbed on parent mordenite is the lowest due to the poor acid site accessibility and to the limited amount of surface silanol groups (Figure 8A, black solid). The collidine adsorption increases after acid or fluoride etching (Figure 8A, blue and red solid). The highest amount of collidine is adsorbed after a consecutive oxalic acid and fluoride etching (Figure 8A, pink solid), which is unambiguous proof of the higher accessibility achieved (Table 2). 

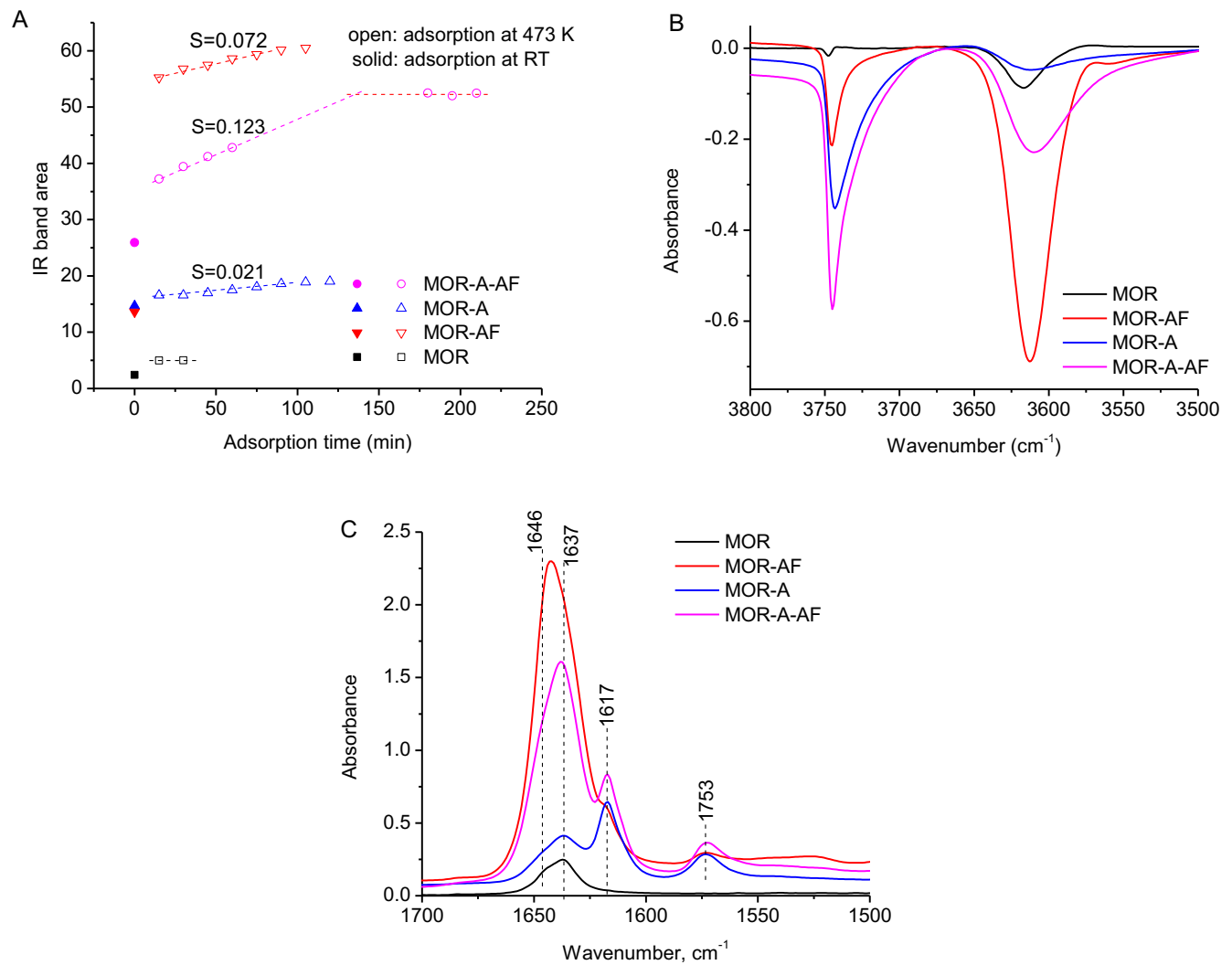

Figure 8. (A) The increase of the peak intensity (the integration of $1573,1617,1637$ and $1648 \mathrm{~cm}^{-1}$ bands, see Figure S4) with time during the adsorption of collidine on mordenite zeolites. (B) The negative peaks show the portion of silanol groups (3745 $\left.\mathrm{cm}^{-1}\right)$ and acidic hydroxyl groups $\left(3585-3610 \mathrm{~cm}^{-1}\right)$ that are interacting with physical or chemical adsorbed collidine at the state of steady adsorption (Figure 8C). (C) IR spectra of collidine adsorbed on the mordenite zeolites at the state of steady adsorption.

After reaching a collidine pressure of 1 torr at RT, the sample was heated at $200{ }^{\circ} \mathrm{C}$ in the collidine atmosphere until reaching a steady adsorption state. In general, the heating helps the diffusion of molecules with a kinetic diameter close to the zeolite pore to diffuse. However, the adsorption of collidine on MOR increased only a little after 15 min of activation (Figure 8A). The comparison of the spectra reveals that the adsorption of collidine on this sample reached already a steady state within $15 \mathrm{~min}$ 
(Figure 8A and Figure S4A, S5A). The $3610 \mathrm{~cm}^{-1}$ band of this sample remained strong (Figure S4A), and the corresponding collidine adsorption band is very weak (Figure 8C). Obviously, it is difficult for collidine to reach the acidic groups inside MOR zeolite framework even under activation at $200{ }^{\circ} \mathrm{C}$.

The adsorption of collidine on MOR-A increased slightly after activation at $200{ }^{\circ} \mathrm{C}$ (Figure 8A, blue open), as the adsorbed collidine mainly interacts with Brønsted acid sites (Figure S4B, S5B). Interestingly, MOR-A keeps adsorbing collidine, slowly but steadily (slope 0.021 ), until reaching a steady state after $105 \mathrm{~min}$ of activation (Figure 8A). Finally, the $1637-1648 \mathrm{~cm}^{-1}$ band intensity of this sample is higher than that of MOR at the equilibrium adsorption state (Figure $8 \mathrm{C}$ ). This information, combined with the fact that the $\mathrm{Si} / \mathrm{Al}$ ratio of MOR-A is more than 4 times higher than that of MOR (Table 1), shows unambiguously that the oxalic acid leaching has improved the diffusion of collidine towards the microporous channels of MOR-A. As a result, much more collidine can be adsorbed on its external surface (Figure 8B, C), Furtherly, bulky molecules like collidine can penetrate easily and be absorbed in the micropores of MOR-A.

The impact of heating on the sorption of collidine on MOR-AF and MOR-A-AF samples is much more pronounced. The $1637-1648 \mathrm{~cm}^{-1}$ band intensity of MOR-AF increases sharply after the first 15 min of activation at $200{ }^{\circ} \mathrm{C}$ (Figure $8 \mathrm{~A}$ and Figure S4C), then the sorption increases continuously (slope 0.072) in the following $75 \mathrm{~min}$ (Figure 8A, red open). The amount of collidine absorbed on MOR-AF at steady state is 12 times higher than that on MOR (Figure 8A, red open). The presence of the very strong negative $3610 \mathrm{~cm}^{-1}$ band (Figure $8 \mathrm{~B}$ ), coupled with the presence of the very strong $1637-1648 \mathrm{~cm}^{-1}$ peaks (Figure 8C), shows clearly that a large portion of the Brønsted acid sites inside zeolite crystals are perturbed by collidine (Figure S5C). In 
the case of MOR-A-AF, the intensity of the $1637-1648 \mathrm{~cm}^{-1}$ bands also increases obviously after heating at $200^{\circ} \mathrm{C}$ for $15 \mathrm{~min}$ (Figure $8 \mathrm{~A}$ and Figure S4D, S5D). The sorption of collidine on this sample continuously increases in the next 120 min, with the highest slope (slope 0.123 ) amongst all samples (Figure 8A, pink open).

After establishing a steady absorption state, the collidine was desorbed under vacuum upon increasing the temperature. During the process, the 1573 and $1617 \mathrm{~cm}^{-1}$ bands disappear first (Figure S6). Meanwhile, the 1637-1648 $\mathrm{cm}^{-1}$ bands loss intensity progressively (Figure S6). Based on the spectra collected after desorption at $250{ }^{\circ} \mathrm{C}$ (Figure S6D), the acid amount of MOR, MOR-A, MOR-AF, and MOR-A-AF were quantified as 49, 82, 418 and $326 \mu \mathrm{mol} \mathrm{g}^{-1}$, respectively (Table 2). Based on the $\mathrm{Si} / \mathrm{Al}_{\text {ICP }}$ ratio, however, the estimate acid amount of these samples is 2222, 556, 2222 and $800 \mu \mathrm{mol} \mathrm{g}{ }^{-1}$, respectively (Table 2). Accordingly, the portions of acid sites that are accessible for collidine in the case of MOR, MOR-A, MOR-AF, and MOR-A-AF are 2, 15, 19 and 41\%, respectively (Table 2). This result highlites what level of accessibility for a bulky molecule such as collidine could be acheived by oxalic acid, $\mathrm{NH}_{4} \mathrm{~F}$ and combined oxalic acid - ammonium fluoride treatment. Noticeably, even the acid sites inside the side pockets of MOR-A-AF are accessible to collidine. A strong argument is the asymmetric nature of the negative peaks $\left(3610 \mathrm{~cm}^{-1}\right.$, Figure $\left.8 \mathrm{~B}\right)$ in the case of MOR-A-AF. The deconvolution of the negative peak of MOR-A-AF shows that about $40 \%$ of acidic hydroxyl groups interacting with collidine is situated in the side pockets, i.e., corresponds to the band at $3590 \mathrm{~cm}^{-1}$.

\subsection{Defect engineered mesopore formation}

The introduction of mesopores in a microporous zeolite crystal requires partial removal of framework atoms. Whatever the post-synthesis method employed, desilication [37], dealumination [38] or demetallation [9], the introduction of 
secondary porosity involves a partial breakage of framework $\mathrm{Si}-\mathrm{O}-\mathrm{Al}$ and/or $\mathrm{Si}-\mathrm{O}-\mathrm{Si}$

bonds. The features of the added porosity (pore size, shape, volume, interconnectivity, spatial distribution...) are therefore determined by the ease of breaking the T-O-T bonds [5].

The crystallographically imperfect zones are rich in coordination unsaturated or strained framework sites, which bear much higher internal energy and hence are much more vulnerable to chemical attack. Naturally, this serves as the origin for the development, through the partial dissolution of zeolite framework, of interstitial and intra-particle secondary porosity in zeolite framework [10]. Because of this, the dissolution of mordenite zeolites in $\mathrm{NH}_{4} \mathrm{~F}$ solution results in the formation of interparticle "cracks" and intra-crystalline mesopores (Figure 6, 7). Specifically, the interface between intergrown crystallites leads to separated nano crystals (Figure 6CE). And the presence of the hidden mosaic structures allows the engineering of zeolite poorsity at meso sized scales, which lead directly to intra-particle mesopores formation (Figure 7A-C). At the same time, this also shows that the primary dissolution behavior of a zeolite crystal has already been preset by zeolite synthesis history $[10,11,39-41]$.

The acid-leaching induced defects, introduced by oxalic acid extraction of framework aluminium, changed the dissolution behavior of zeolite crystals substantially. This is evidenced by the fact that the mesoporosity of MOR-AF and MOR-A-AF is very different from each other, as revealed by electron microscopy and quantified by high resolution nitrogen physisorption analysis (Figure 2, Figure 5-7 and Table 1). Although the removal of framework Al by oxalic acid does not increase substantially the pore volume of zeolite (Table 1), it results in a remarkable improvement of the inter-/intra- particle absorption and diffusion of chemical 
molecules [42]. In the present study, this has been demonstrated unambiguously through the collidine absorption experiment (Figure 8A).

As a result of the significant presence of framework defects and the substantially improved intra-particle diffusion efficiency, the dissolution of MOR-A is much faster than the parent mordenite due to the improved uptake of reactive species and presence of defects that favor the dissolution of the framework. In line with this, the MOR-A is more deeply etched and shows $14 \%$ lower product yield than the parent zeolite (Table 1). Also as a result of the improved diffusion and dissolution, more mesopores with much smaller pore size are formed in the MOR-A-AF sample as compared to the MOR-AF (Figure 5C, D and Figure 7A, C, D).
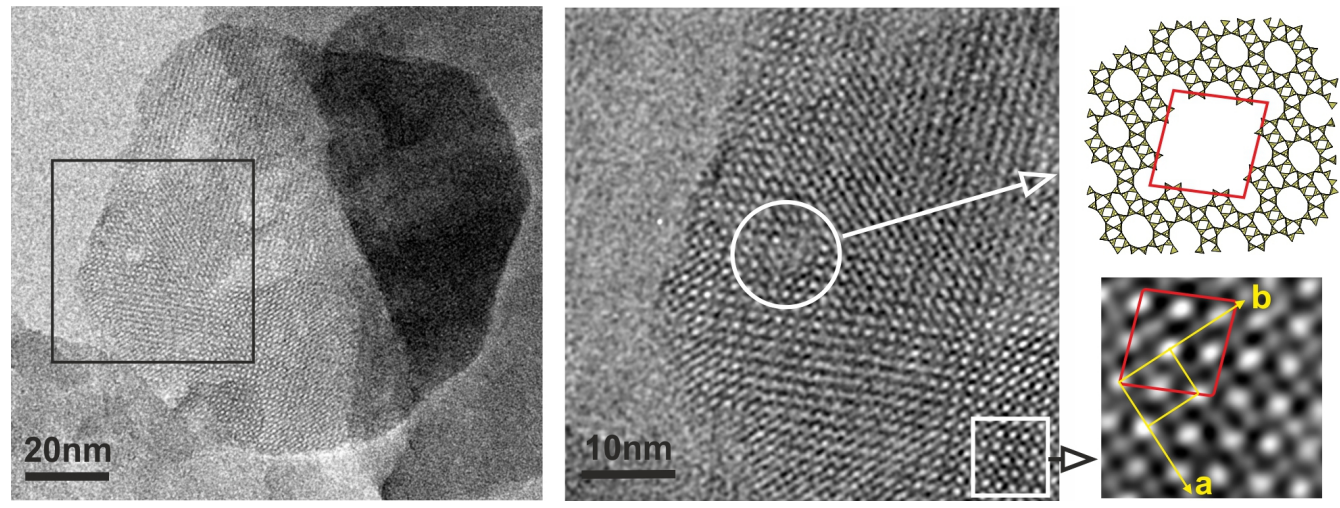

Figure 9 A high resolution TEM image of MOR-A-AF demonstrating the presence of a defect-induced mesopore.

Besides, the framework defects left by the selective $\mathrm{Al}$ removal function as starting points for framework dissolution. These defects are spatially more accessible and energetically more favorable sites for dissolution. We have observed that the number of internal silanols $\left(3734 \mathrm{~cm}^{-1}\right.$ on the $\mathrm{OH}-\mathrm{IR}$ spectra, Figure 4) on MOR-A-AF decreased with respect to its precursor, MOR-A (Figure 4 and Figure S7), which supports our interpretation of the role of defect sites in $\mathrm{NH}_{4} \mathrm{~F}$ etching. We have also analyzed the small and ill-defined pores by high resolution TEM and found intensive 
and localized dissolution of zeolite framework (Figure 9). Furthermore, the Si/Al ratio of MOR-A-AF decreased (ca. 20) in respect to MOR-A (ca. 29) (Table 1). This apparent "desilication" behavior sharply contrasts the general observations that fluorides, especially the concentrated $\mathrm{NH}_{4} \mathrm{~F}$ solutions, remove $\mathrm{Si}$ and $\mathrm{Al}$ equally from zeolite frameworks $[8-11,43]$. Hence, the only plausible explanation is that during the $\mathrm{NH}_{4} \mathrm{~F}$ etching of MOR-A, the dissolution starts preferentially at the defect sites left by Al removal, i.e., the Si-rich and highly defected by the Al extraction regions. Accordingly, these artificial defects function as independent embryo of small and irregular mesopores, as shown in Figure 7D and Figure 9. Thanks to the presence of these chemically induced defects, small mesopores can now be conveniently introduced to the framework of nano-sized separate particles that are most likely coherent crystal domains in nature (figure 7D).

The set of our experimental data shows that the formation of mesopores under the present conditions involves two independent and synergistic pathways. The defects already present in MOR lead to the fragmentation of previously aggregated domains and the selective removal of hitherto hidden nano-crystals; this is the so-called mosaic structure of the zeolite [10]. The artificial defects introduced by partial removal of framework $\mathrm{Al}$ serve as additional sites versatile for the enhanced dissolution of zeolite structure. Thus by carrying out a pretreatment on the as-synthesized zeolite before implementing the intended changes, one can effectively overcome the chemical or structural limitation predefined by zeolite synthesis history. In this way, it allows us to further explore the potential of post-synthesis modification in engineering and designing advanced zeolite materials for various applications.

\subsection{Dealkylation of 1,3,5-Triisopropylbenzene on the parent and modified mordenite zeolites}


In the dealkylation of 1,3,5-triisopropylbenzene (TiPBz, kinetic diameter 9.5 $\AA$ ), a bulky molecule reacting mainly on the external surface of zeolites, MOR shows an initial conversion of $66 \%$ followed by a fast deactivation (Figure 10). MOR-AF samples start with a $10 \%$ higher initial conversion than MOR, and the activity stability is substantially improved. Considering that the intrinsic microporosity is not impacted by $\mathrm{NH}_{4} \mathrm{~F}$ etching, the improved conversion of $\mathrm{TiPBz}$ is therefore attributed to more exposure of crystal external surface (Table 1) as a result of the decrease of the microporous domain size.

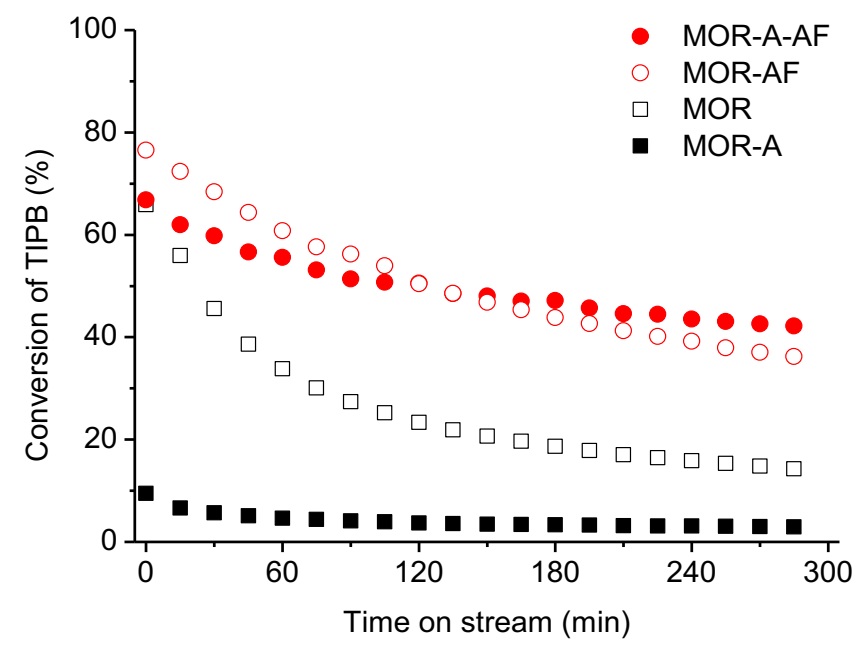

Figure 10. Conversion of 1,3,5-triisopropylbenzene as a function of the catalyst time on stream on MOR (open square), MOR-A (solid square), MOR-AF (open circle), and MOR-A-AF (solid circle). $\mathrm{T}=350{ }^{\circ} \mathrm{C}, \mathrm{P}=0.101 \mathrm{MPa}, \mathrm{W} / \mathrm{F}_{0}=95 \mathrm{~kg} \cdot \mathrm{s} \cdot \mathrm{mol}^{-1}$.

The initial TiPBz conversion on MOR-A is only about $10 \%$ (Figure 10), although this sample shows almost twice higher collidine acidity than MOR. Apparently, although the acid leaching is helpful for the intraparticle diffusion of pyridine and collidine (Table 2, Figure 8A), it is not enough to improve the diffusion of a bulkier molecular such as TiPBz. The drop in the activity is also due to the extraction of aluminium from the external surface of zeolite. 
The initial TiPBz conversion on MOR-A-AF increases to $67 \%$ (Figure 10), more than 6 times higher than its counterpart MOR-A, and comparable to the parent mordenite. It is worth mentioning that the Al content of MOR sample is three times higher than that of MOR-A-AF (Table 1). This result suggests that some of the active sites located inside the MOR-A-AF crystals are accessible to TiPBz. These data illustrate the potential of defect-induced dissolution of zeolite framework to control and improve the catalytic performances of zeolites.

\section{Conclusions}

An in-depth study of the dissolution behavior of MOR-type zeolite under consequtive oxalic acid and $\mathrm{NH}_{4} \mathrm{~F}$ treatment is carried out. The role of framework defects in the process of formation of inter- and intra-particle mesopores is identified. The interface between intergrowths is a place for a fast dissolution that leads to separated crystals or inter-particle mesopore formation, revealing the intrinsic hidden mosaic structures of zeolite crystals. These intrinsic defects allow the engineering of zeolite crystals at meso scales and fragmentation of zeolite aggregates of their building parts.

The set of experimentak data reveals that the extrinsic defects, induced by chemical leaching in oxalic acid, generates different type of mesoporosity and can be used to control zeolite accessibility and activity at nanoscale. More precisely, the contribution of the extrinsic defects is twofold. First, they improve the intra-particle diffusion and absorption of chemicals substantially. Second, the defects themselves serve as the initial points for the preferential dissolution of a zeolite framework. As a result, the dissolution of the defect-containing framework is more efficient and uniform. The resultant hierarchical zeolite shows superior mesoporosity in terms of 
mesopore distribution and available mesopore volume and thus substantially improved accessibility to the active sites located inside the micropores. Derived catalysts show outstanding catalytic performance in the catalytic conversion of bulky molecules, as exemplified in the dealkylation of 1,3,5-triisopropylbenzene.

Herein, a simple and potentially universal method for post-synthesis zeolite engineering, which makes zeolite dissolution going beyond the limits set by zeolite structures and synthesis chemistry, is developed. This approach can be extended to other zeolites providing zeolite catalyst and molecular sieves with substantially improved performance.

\section{Acknoweledgements}

The authors acknowledge funding from the Sino-French joint laboratory “Zeolites”. Zhengxing Qin acknowledge the support from NSFC21706285, Qingdao Applied Basic Research Project (19-6-2-70-cg), the Fundamental Research Funds for the Central Universities (18CX02013A), ZQ and SM acknowledge the support from NSFC21991091.

\section{References}

1 C. S. Cundy and P. A. Cox, Chemical Reviews, 2003, 103, 663-702.

2 B. Smit and T. L. M. Maesen, Nature, 2008, 451, 671-678.

3 K. Möller and T. Bein, Chemical Society Reviews, 2013, 42, 3689-3707.

4 W. Schwieger, A. G. Machoke, T. Weissenberger, A. Inayat, T. Selvam, M. Klumpp and A. Inayat, Chemical Society Reviews, 2016, 45, 3353-3376.

5 S. Mitchell, A. B. Pinar, J. Kenvin, P. Crivelli, J. Kärger and J. Pérez-Ramírez, Nature Communications, 2015, 6, 8633. 
6 M.-C. Silaghi, C. Chizallet, J. Sauer and P. Raybaud, Journal of Catalysis, 2016, 339, 242-255.

7 G. Centi and S. Perathoner, Microporous and Mesoporous Materials, 2008, 107, 3-15. V. Valtchev, J.-P. Gilson and Z. QIN, US20180194635A1, Assigned to Centre National de la Recherche Scientifique (CNRS).

8 Z. Qin, L. Lakiss, J. P. Gilson, K. Thomas, J. M. Goupil, C. Fernandez and V. Valtchev, Chemistry of Materials, 2013, 25, 2759-2766.

9 Z. Qin, J.-P. Gilson and V. Valtchev, Current Opinion in Chemical Engineering, 2015, 8, 1-6.

10Z. Qin, G. Melinte, J.-P. Gilson, M. Jaber, K. Bozhilov, P. Boullay, S. Mintova, O. Ersen and V. Valtchev, Angewandte Chemie International Edition, 2016, 55, 15049-15052.

11Z. Qin, L. Pinard, M. A. Benghalem, T. J. Daou, G. Melinte, O. Ersen, S. Asahina, J.-P. Gilson and V. Valtchev, Chemistry of Materials, 2019, 31, $4639-4648$.

12Z. Qin, K. A. Cychosz, G. Melinte, H. El Siblani, J.-P. Gilson, M. Thommes, C. Fernandez, S. Mintova, O. Ersen and V. Valtchev, Journal of the American Chemical Society, 2017, 139, 17273-17276.

13 J. Jiang, J. Yu and A. Corma, Angewandte Chemie International Edition, 2010, 49, 3120-3145.

14 C. Zhang, E. Kapaca, J. Li, Y. Liu, X. Yi, A. Zheng, X. Zou, J. Jiang and J. Yu, Angewandte Chemie International Edition, 2018, 57, 6486-6490. 
15F. Thibault-Starzyk, A. Vimont and J.-P. Gilson, Catalysis Today, 2001, 70, $227-241$.

16Z. Qin, L. Lakiss, L. Tosheva, J.-P. Gilson, A. Vicente, C. Fernandez and V. Valtchev, Advanced Functional Materials, 2014, 24, 257-264.

17 P. Losch, A. B. Pinar, M. G. Willinger, K. Soukup, S. Chavan, B. Vincent, P. Pale, B. Louis, Journal of Catalysis, 2017, 345, 11-23.

18C. J. Humphreys, in Introduction to Analytical Electron Microscopy, eds. J. J. Hren, J. I. Goldstein and D. C. Joy, Springer US, Boston, MA, 1979, pp. 305332.

19P. Simoncic and T. Armbruster, American Mineralogist, 2004, 89, 421-431.

20 B. Li, J. Xu, B. Han, X. Wang, G. Qi, Z. Zhang, C. Wang and F. Deng, The Journal of Physical Chemistry C, 2013, 117, 5840-5847.

21 D. B. Rasmussen, J. M. Christensen, B. Temel, F. Studt, P. G. Moses, J. Rossmeisl, A. Riisager and A. D. Jensen, Angewandte Chemie International Edition, 2015, 54, 7261-7264.

22 P. Cheung, A. Bhan, G. J. Sunley and E. Iglesia, Angewandte Chemie International Edition, 2006, 45, 1617-1620.

23 V. L. Sushkevich, D. Palagin and J. A. van Bokhoven, Angewandte Chemie International Edition, 2018, 57, 8906-8910.

24 W. Zhou, J. Kang, K. Cheng, S. He, J. Shi, C. Zhou, Q. Zhang, J. Chen, L. Peng, M. Chen and Y. Wang, Angewandte Chemie, 2018, 130, 12188-12192.

25 Y. Xu, X. Shen, C. Peng, Y. Ma, L. Han, P. Wu, H. Peng and S. Che, Science China-Materials, 2018, 61, 1185-1190. 
26 J. Pastvova, D. Kaucky, J. Moravkova, J. Rathousky, S. Sklenak, M. Vorokhta, L. Brabec, R. Pilar, I. Jakubec, E. Tabor, P. Klein and P. Sazama, ACS Catalysis, 2017, 7, 5781-5795.

27 H. Issa, J. Toufaily, T. Hamieh, J. D. Comparot, A. Sachse and L. Pinard, Journal of Catalysis, 2019, 374, 409-421.

28 M. Boronat, C. Martínez-Sánchez, D. Law and A. Corma, Journal of the American Chemical Society, 2008, 130, 16316-16323.

29H. Xue, X. Huang, E. Ditzel, E. Zhan, M. Ma and W. Shen, Industrial \& Engineering Chemistry Research, 2013, 52, 11510-11515.

30 D. V. Peron, V. L. Zholobenko, J. H. S. de Melo, M. Capron, N. Nuns, M. O. de Souza, L. A. Feris, N. R. Marcilio, V. V. Ordomsky, A. Y. Khodakov, Microporous and Mesoporous Materials, 2019, 286, 57-64.

31 R. Giudici, H. W. Kouwenhoven and R. Prins, Applied Catalysis A: General, 2000, 203, 101-110.

32 M. Thommes, K. Kaneko, A. V. Neimark, J. P. Olivier, F. Rodriguez-Reinoso, J. Rouquerol and K. S. W. Sing, Pure and Applied Chemistry, 2015, 87, 10511069.

33 C. A. Fyfe, J. M. Thomas, J. Klinowski and G. C. Gobbi, Angewandte Chemie International Edition in English, 1983, 22, 259-275.

34 M. Müller, G. Harvey and R. Prins, Microporous and Mesoporous Materials, $2000, \mathbf{3 4}, 135-147$. 
35 N. S. Nesterenko, F. Thibault-Starzyk, V. Montouillout, V. V. Yuschenko, C. Fernandez, J. P. Gilson, F. Fajula and I. I. Ivanova, Microporous and Mesoporous Materials, 2004, 71, 157-166.

36F. Thibault-Starzyk, I. Stan, S. Abelló, A. Bonilla, K. Thomas, C. Fernandez, J.-P. Gilson and J. Pérez-Ramírez, Journal of Catalysis, 2009, 264, 11-14.

37D. Verboekend and J. Pérez-Ramírez, Catalysis Science \& Technology, 2011, 1, 879-890.

38 S. van Donk, A. H. Janssen, J. H. Bitter and K. P. de Jong, Catalysis Reviews, 2003, 45, 297-319.

39 S. Svelle, L. Sommer, K. Barbera, P. N. R. Vennestrøm, U. Olsbye, K. P. Lillerud, S. Bordiga, Y.-H. Pan and P. Beato, Catalysis Today, 2011, 168, 3847.

40 D. Fodor, A. Beloqui Redondo, F. Krumeich and J. A. van Bokhoven, The Journal of Physical Chemistry C, 2015, 119, 5447-5453.

41 D. Fodor, F. Krumeich, R. Hauert and J. A. van Bokhoven, Chemistry - A European Journal, 2015, 21, 6272-6277.

42 S. van Donk, J. H. Bitter, A. Verberckmoes, M. Versluijs-Helder, A. Broersma and K. P. de Jong, Angewandte Chemie International Edition, 2005, 44, 13601363.

43 X. Chen, A. Vicente, Z. Qin, V. Ruaux, J.-P. Gilson and V. Valtchev, Chemical Communications, 2016, 52, 3512-3515. 